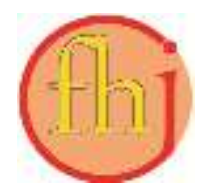

Faletehan Health Journal, 8 (3) (2021) 147-151

www. journal.Ippm-stikesfa.ac.id/ojs/index.php/FHJ

ISSN 2088-673X | e-ISSN 2597-8667

\title{
Penurunan Kecemasan Ibu dengan Mengikuti Kelas Ibu Hamil Prenatal Yoga
}

\author{
Indah Nurfazriah ${ }^{1^{*}}$, Innama Sakinah ${ }^{1}$ \\ ${ }^{1}$ Fakultas Ilmu Kesehatan, Universitas Faletehan \\ *Corresponding Author: iendah_ceriel@yahoo.com
}

\begin{abstract}
Abstrak
Permasalahan kematian ibu merupakan masalah serius yang dihadapi oleh Kementerian Kesehatan. Kematian ibu banyak terjadi pada periode intranatal dan post natal. Hal ini dapat disebabkan salah satunya karena ketidaksiapan ibu dalam menghadapi proses persalinan sehingga informasi terkait kehamilan, persalinan dan nifas belum diketahui oleh ibu secara lengkap dan up to date. Informasi terkait kehamilan, persalinan dan nifas bisa didapatkan melalui kunjungan antenatal khususnya dalam pelaksanaan kelas ibu hamil. Tujuan dari penelitian ini untuk mengetahui perbedaan kecemasan ibu hamil trimester III dalam menghadapi persalinan sebelum dan sesudah mengikuti kelas ibu hamil dengan prenatal yoga di puskesmas Ciruas Kabupaten Serang tahun 2018. Metode yang digunakan dalam penelitian ini adalah penelitian Pre Eksperimen design one-group pre test dan post test. Hasil penelitian menunjukkan sebagian besar kelompok usia 20-35 tahun yaitu 21 orang (70\%), untuk paritas ibu terbanyak dari multigravida yaitu 20 orang (67\%). Tingkat kecemasan ibu dalam menghadapi persalinan sebagian besar memiliki kecemasan sedang sebanyak 25 ibu hamil $(83,3 \%)$, dan setelah mengikuti kelas ibu hamil dengan prenatal yoga tingkat kecemasan ibu sebagian besar memiliki kecemasan ringan yaitu 27 ibu hamil (90\%). Penelitian ini menunjukkan bahwa kelas ibu hamil dengan prenatal yoga memiliki pengaruh terhadap penurunan angka kejadian kecemasan ibu hamil menghadap persalinan.

Kata Kunci: Prenatal Yoga, Kecemasan Ibu, Persalinan
\end{abstract}

\section{The Decrease of Maternal Anxiety by Joining Prenatal Yoga Classes}

\begin{abstract}
The issue of maternal mortality is a serious problem faced by the Ministry of Health. Many maternal deaths occurred in the intra-natal and post-natal period. This could be due to unpreparedness of the mothers in facing the labor process so that information related to pregnancy, childbirth and postnatal period was not fully and up to date known by them. Information related to pregnancy, childbirth and postpartum can be obtained through antenatal visits, especially by the implementation of antenatal classes. The purpose of this study was to determine the anxiety differences of third trimester pregnant mothers in facing childbirth before and after participating prenatal yoga classes at Ciruas Public Health Center, Serang Regency in 2018. The method used in this study was pre-experimental research design one-group pre-test and post-test. The results showed most participants were the age group 20-35 years, namely 21 people (70\%) and the most maternal parity is multigravidas, namely 20 people (67\%). The level of maternal anxiety in facing childbirth were mostly moderate as many as 25 pregnant mothers (83.3\%), and after participating prenatal yoga classes, most of the mothers had mild anxiety, namely 27 pregnant women (90\%). To conclude, prenatal yoga classes are effective on reducing the incidence of maternal anxiety in facing childbirth.
\end{abstract}

Keywords: Prenatal Yoga, Maternal Anxiety, Childbirth 


\section{Pendahuluan}

Program pembangunan kesehatan di Indonesia dewasa ini masih diprioritaskan pada upaya peningkatan derajat kesehatan ibu dan anak, yaitu ibu hamil, bersalin dan bayi. Hal ini disebabkan masih tingginya Angka Kematian Ibu (AKI) dan Angka Kematian Bayi (AKB). AKI menggambarkan jumlah wanita yang meninggal dari suatu penyebab kematian terkait dengan gangguan kehamilan atau penanganannya (tidak termasuk kecelakaan atau kasus insidentil) selama kehamilan, melahirkan dan dalam masa nifas (42 hari setelah melahirkan) tanpa memperhitungkan lama kehamilan per 100.000 kelahiran hidup (Kemenkes, Pedoman Kelas Ibu Hamil, 2014).

Hasil dari beberapa studi mengungkapkan bahwa penyebab utama kematian ibu dapat dikelompokkan menjadi penyebab langsung dan penyebab tidak langsung. Penyebab langsung kematian ibu kurang lebih 90\% disebabkan oleh seputar persalinan, dan kematian tersebut terjadi karena komplikasi. Sedangkan penyebab tidak langsung antara lain dilatarbelakangi oleh sosial ekonomi, pendidikan, kedudukan dan peranan wanita, sosial budaya, dan transportasi yang dapat disebabkan ibu terlalu tua untuk mempunyai anak, ibu terlalu muda untuk mempunyai anak, ibu terlalu banyak melahirkan, ibu terlalu sering/rapat jarak melahirkan, terlambat mengenal tanda bahaya dan mengambil keputusan, terlambat membawa dan mencapai fasilitas kesehatan, serta terlambat mendapat pertolongan di fasilitas kesehatan (Aeni, 2013).

Indikator cakupan K4 memperlihatkan akses ibu hamil terhadap pelayanan kesehatan dan tingkat kepatuhan ibu hamil dalam memeriksakan kehamilannya ke tenaga kesehatan. Secara nasional, indikator cakupan pelayanan kesehatan ibu hamil K4 pada tahun 2013 yaitu sebesar $86,85 \%$ belum mencapai target Rencana Strategis (Renstra) Kementerian Kesehatan (Kemenkes) tahun yang sama yakni sebesar 93\% (Kemenkes, 2017). Permasalahan kematian ibu di Indonesia merupakan masalah serius yang dihadapi oleh Kementerian Kesehatan. Kematian ibu banyak terjadi pada masa nifas yang dapat disebabkan karena perawatan masa nifas yang dilakukan oleh ibu kurang optimal, sehingga masa nifas merupakan masa yang rawan akan kematian. Pemerintah mengatasi permasalahan tersebut dengan metode pembelajaran kelas ibu hamil
(Kemenkes, 2017).

Kelas ibu hamil adalah kegiatan untuk membahas materi buku KIA dalam bentuk tatap muka kelompok yang diikuti diskusi dan tukar pengalaman antara ibu-ibu hamil dan petugas kesehatan. Kelas Ibu hamil bertujuan untuk meningkatkan pengetahuan dan keterampilan ibu, salah satunya dalam perawatan masa nifas (Kemenkes, Pedoman Kelas Ibu Hamil, 2014). Kelas ibu hamil merupakan sarana untuk belajar bersama tentang kesehatan bagi ibu hamil, dalam bentuk tatap muka dalam kelompok yang bertujuan untuk meningkatkan pengetahuan dan ketrampilan ibu-ibu mengenai kehamilan, persalinan, nifas, KB pasca persalinan, pencegahan kompllikasi, perawatan bayi baru lahir dan aktivitas fisik/ senam hamil (Setyaningsih, Fitriyani, \& Ersila, 2016).

\section{Metodologi Penelitian}

Jenis penelitian ini adalah Pre Eksperimen design one-group pre test dan post test, dan menggunakan alat ukur STAI from Y-1 (A-State) untuk menilai tingkat kecemasan pada ibu hamil trimester III. Populasi dalam penelitian ini yaitu seluruh ibu hamil yang melakukan pemeriksaan kehamilan di wilayah kerja Puskesmas Ciruas Kabupaten Serang pada bulan April-Juli Tahun 2018. Teknik pengambilan sampel penelitian ini yaitu dengan menggunakan total sampling yaitu seluruh ibu hamil trimester III yang melakukan pemeriksaan kehamilan pada bulan April tahun 2018 sejumlah 30 orang. Tujuan dari penelitian ini yaitu untuk mengetahui perbedaan kecemasan ibu dalam menghadapi persalianan sebelum dan sesudah mengikuti kelas ibu hamil dengan Prenatal Yoga.

Kegiatan dalam kelas ibu hamil ini yaitu dengan memberikan materi buku KIA dalam bentuk tatap muka secara kelompok yang diikuti dengan mendiskusikan dan bertukar pengalaman antara ibu hamil dan petugas kesehatan, di kelas ini ibu-ibu hamil akan belajar bersama, berdiskusi dan bertukar pengalaman, tentang kesehatan ibu dan anak (KIA) secara menyeluruh dan sistematis dilaksanakan secara terjadwal dan berkesinambungan, setelah berdiskusi tim fasilitator memberikan latihan senam hamil dengan prenatal yoga yang bertujuan untuk memberikan rasa rileks dan tenang dalam menjalani kehamilanya. Kelas ibu hamil difasilitasi oleh bidan/tenaga kesehatan dengan menggunakan 
Faletehan Health Journal, 8 (3) (2021) 147-151

www. journal.Ippm-stikesfa.ac.id/ojs/index.php/FHJ

ISSN 2088-673X | 2597-8667

paket kelas ibu hamil, yang terdiri atas buku KIA, lembar balik (flip chart), pedoman pelaksanaan kelas ibu hamil, pegangan fasilitator kelas ibu hamil, dan buku senam ibu hamil. Fasilitator dalam kelas ibu hamil ini adalah bidan yang telah mendapakan pelatihan fasilitator kelas ibu hamil atau melalui on job training (Kemenkes, Pedoman Kelas Ibu Hamil, 2014).

\section{Hasil dan Pembahasan \\ Gambaran Kelas Ibu Hamil di Puskesmas Ciruas Kabupaten Serang}

Pelaksanaan kelas ibu hamil diikuti oleh ibu hamil yang berada di sekitar wilayah kerja Puskesmas Ciruas. Sebelum kegiatan berlangsung dilakukan pemeriksaan kehamilan terlebih dahulu, setelah itu ibu diberikan kuesioner penelitian sebelum kegiatan untuk mengetahui kesiapan ibu dalam menghadapi persalinan. Inti dari pelaksanaan kegiatan kelas ibu hamil ini ibu diberikan materi terkait kesehatan ibu dan anak dari mulai kehamilan, persalinan, masa nifas, bayi baru lahir dan keluarga berencana. Selain pemberian materi, ibu didampingi dalam melakukan senam hamil yaitu prenatal yoga dengan tujuan memberikan rasa nyaman, merileksasikan serta meregangkan otot - otot panggul ibu. Secara keseluruhan kegiatan kelas ibu hamil berlangsung selama 2-3 jam, pertemuan dilakukan sebanyak 2 kali. Adapun alat ukur yang digunakan untuk mengetahui tingkat kecemasan ibu dalam menghadapi persalinan adalah STAI From Y-1 (A-State) bertujuan untuk menjaring informasi mengenai taraf kecemasan individu pada suatu peristiwa atau hal tertentu. Selain itu skala trait dari STAI telah menunjukkan reliabilitas testrecest excellent. Penentuan derajat kecemasan dilakukan dengan cara menjumlahkan nilai pertanyaan 1 hingga 20 dengan hasil yaitu: jika skor < 40 kecemasan ringan/rendah, skor 40-60 ecemasan sedang, skor $>60$ kecemasan tinggi.

\section{Karakteristi Responden}

Adapun karakteristik responden yang mengikuti penelitian ini ditunjukkan dalam tabel 1:

Berdasarkan tabel 1 diketahui bahwa dari 30 responden sebagian besar berada pada kelompok umur 20-35 tahun yaitu sebanyak 21 orang (70\%) dan paritas Multigravida sebanyaj 20 orang (67\%).
Tabel 1: Distribusi Frekuensi Ibu Hamil Berdasarkan Umur dan Paritas $(\mathrm{n}=30)$

\begin{tabular}{lcc}
\hline \multicolumn{1}{c}{ Variabel } & N & $\%$ \\
\hline Umur & & \\
$<20$ tahun & 4 & 13 \\
$20-35$ tahun & 21 & 70 \\
$>35$ tahun & 5 & 17 \\
\hline Paritas & & \\
Primigravida & 10 & 33 \\
Multigravida & 20 & 67 \\
\hline
\end{tabular}

Berdasarkan kategori umur, hasil penelitian ini sama seperti hasil penelitian yang dilakukan di Yogyakarta yang menunjukkan sebagian besar ibu berumur antara 20-27 tahun (54,6\%). Penelitian tersebut menunjukkan adanya hubungan yang bermakna antara umur ibu dengan kesiapan dalam menghadapi persalinan (Sari \& Puspitasari, 2016). Kategori umur ini merupakan usia reproduktif bagi wanita. Pada usia ini wanita lebih mampu berpikir kritis dan matang dalam pengambilan keputusan, begitu halnya dengan kesiapan ibu dalam melahirkan. Kelompok umur 20-35 tahun termasuk juga kelompok dewasa. Pada fase ini seseorang dapat menjadi produktif dan kreatif, karena memiliki kesempatan dalam mengembangkan potensi yang ada dalam dirinya, serta mampu bersikap secara kondisional terhadap perubahan dan sesuatu yang baru, namun terkadang bersikap kaku dan egois terhadap hal yang baru. Sikap ini dapat dipengaruhi oleh keterlibatan keluarga serta lingkungan yang mendukung. Usia/umur akan menentukan rasa keingintahuan seseorang, semakin muda usia seseorang semakin besar rasa ingin tahu dari diri individu tersebut dalam memperoleh dan menggali informasi. Dengan bertambahnya umur seseorang akan terjadi perubahan asfek fisik maupun psikologis (mental), karena aspek psikologis merupakan taraf berfikir seseorang semakin matang dan dewasa. (Saidah, 2016)

Penelitian ini juga menunjukkan bahwa sebagain besar ibu adalah multigravida. Multigravida yaitu ibu yang sudah pernah hamil ataupun yang sudah melahirkan 1 atau lebih dari 1 anak, sehingga ibu mempunyai pengalaman dari kehamilan ataupun proses persalinan sebelumnya. Pada paritas multigravida ibu lebih siap untuk menghadapi persalinan, hal ini sesuai dengan teori yang dikemukakan oleh Depkes (2012) bahwa paritas merupakan salah satu faktor yang menjadi 
predisposisi pelayanan antenatal. Semakin tinggi paritas ibu semakin tinggi dan banyak pengalaman yang ibu peroleh sehingga kecemasan serta ketakutan dalam menghadapi persalinan berkurang dan ibu lebih siap dalam menghadapi persalinan. (Qurniasih, 2014).

Berbeda dengan hasil penelitian ini, penelitian yang dilakukan oleh Sari \& Puspitasari (2016) dimana pada hasil penelitian tersebut Sebagian besar responden yang mengikuti kelas ibu hamil adalah pada kelompok paritas Primigravida $(79,2 \%)$. Terlihat perbedaan yang signifikan pada kelompok paritas primigravida untuk kesiapan dalam menghadapi persalinan yang dapat dipengaruhi oleh rasa keingintahuan ibu primigravida dalam mengikuti kelas antenatal. Hasil penelitian yang dilakukan oleh (Fajrin, 2017) mengenai hubungan paritas dengan tingkat kecemasan ibu hamil trimester III dalam menghadapi persalinan menunjukkan terdapat hubungan paritas dengan tingkat kecemasan ibu hamil trimester III dalam menghadapi persalinan. Pengalaman persalinan merupakan faktor yang dapat dihubungkan dengan kesiapan ibu, karena jika pengalaman ibu kurang matang dan ibu mengalami kecemasan yang berlebihan maka kesiapan ibu dalam menghadapi persalinan sangat kurang.

\section{Kecemasan Ibu dalam Menghadapi Persalinan Sebelum dan Sesudah Dilakukan Kelas Ibu Hamil dengan Prenatal Yoga}

Perubahan kategori cemas ibu yang mengikuti kelas ibu hamil pada penelitian ini digambarkan pada tabel berikut:

Tabel 2: Distribusi Frekuensi Pre dan Post Test Kecemasan Pada Ibu dalam Menghadapi Persalinan Yang Mengikuti Kelas Ibu Hamil dengan Prenatal Yoga Di Puskesmas Ciruas Kabupaten Serang Tahun 2018

\begin{tabular}{lcccc}
\hline \multirow{2}{*}{$\begin{array}{c}\text { Kecemasan Ibu } \\
\text { Hamil Trimester III }\end{array}$} & \multicolumn{2}{c}{ PreTest } & \multicolumn{2}{c}{ PostTest } \\
\cline { 2 - 5 } & $\mathbf{N}$ & $\mathbf{\%}$ & $\mathbf{N}$ & $\mathbf{\%}$ \\
\hline Kecemasan ringan & 3 & 10 & 27 & 90 \\
\hline Kecemasan Sedang & 25 & 83,3 & 3 & 10 \\
\hline Kecemasan Tinggi & 2 & 6,7 & 0 & 0 \\
\hline Jumlah & $\mathbf{3 0}$ & $\mathbf{1 0 0}$ & $\mathbf{3 0}$ & $\mathbf{1 0 0}$ \\
\hline
\end{tabular}

Berdasarkan Tabel 2 menunjukkan bahwa dari 30 responden tingkat kecemasan ibu dalam menghadapi persalinan sebelum mengikuti kelas ibu hamil dengan prenatal yoga sebagian besar memiliki kecemasan sedang sebanyak 25 ibu hamil $(83,3 \%)$, dan setelah mengikuti kelas ibu hamil dengan prenatal yoga tingkat kecemasan ibu sebagian besar memiliki kecemasan ringan yaitu 27 ibu hamil (90\%).

Kecemasan ibu dalam menghadapi persalinan merupakan suatu kondisi konkrit yang mengancam diri ibu hamil yang menyebabkan perasaan tegang, khawatir, dan takut, maka dari itu ibu hamil berusaha untuk dapat berhasil dalam menghadapi situasi tersebut sebaik-baiknya sampai masa persalinan itu tiba. Adanya perubahan fisiologis yang menimbulkan ketidakstabilan kondisi psikologis selama hamil menumbuhkan kekhawatiran yang terus menerus dalam mengahadapi kelahiran bayi pada primigravida. Perasaan demikian akan terwujud dalam bentuk suatu kecemasan yang pada akhirnya ibu tidak siap dalam menghadapi persalinannya. Kecemasan yang diikuti adanya perasaan bimbang, ada kalanya kurang disadari oleh yang bersangkutan sehingga bertahan lama dalam dirinya yang semakin lama akan memiliki frekuensi dan intensitas yang lebih tinggi (Lowdermilk \& Jensen, 2004).

Penelitian ini sejalan dengan penelitian Sari \& Puspitasari (2016) dalam penelitiannya diarahkan untuk melihat hubungan senam yoga dengan kesiapan fisik dan psikologi ibu hamil dalam menghadapi persalinan di kelas antenatal, dan hasil yang diperoleh yaitu terdapat hubungan yoga dengan kesipan fisik dan psikologis dengan nilai $p$ value $<0,001$. Pengaruh kelas ibu hamil terhadap kecemasan ibu dalam menghadapi persalinan sebelum dan sesudah pelaksanaan kegiatan kelas ibu hamil yaitu terdapat pengaruh yang positif dan sangat signifikan. Kelas ibu hamil yang dipadukan dengan kegiatan senam hamil yaitu prenatal yoga sangat bermanfaat untuk ibu hamil karena kegiatan tersebut mencakup pemberian pendidikan kesehatan seputar kesehatan ibu dan bayi baru lahir, dan dapat merileksasikan kondisi fisik maupun psikologis ibu khususnya trimester III kehamilan.

Hasil penelitian ini ini sejalan dengan hasil penelitian yang dilakukan oleh Saidah (2016) bahwa sebelum diberikan kelas ibu hamil sebagian responden belum siap menghadapi persalinan dengan nilai rata-rata $58,7 \%$ dan setelah kegiatan 
Faletehan Health Journal, 8 (3) (2021) 147-151

www. journal.Ippm-stikesfa.ac.id/ojs/index.php/FHJ

ISSN 2088-673X | 2597-8667

kelas ibu hamil terjadi peningkatan yang cukup signifikan yaitu sebesar 76,5\%. Penurunan tingkat kecemasan ibu dalam menghadapi persalinan dipengaruhi oleh pendidikan kesehatan yang diberikan selama mengikuti kelas ibu hamil. Pada hasil penelitian ini didapatkan bahwa dari 30 subjek penelitian mengikuti kelas ibu hamil dengan tekun dan serius. Secara keseluruhan subjek penelitian sangat berpartisipasi dalam mengikuti kelas ibu hamil baik dari primigravida maupun multigravida dengan usia kehamilan di atas 24 minggu.

Pelaksanaan kelas ibu hamil dapat meningkatkan pengetahuan, merubah sikap dan perilaku ibu agar memahami tentang pemeriksaan kehamilan agar ibu dan janin sehat, persalinan aman, nifas nyaman, ibu selamat, bayi sehat, pencegahan penyakit fisik dan jiwa, gangguan gizi dan komplikasi kehamilan, persalinan dan nifas, serta bayi sehat, perawatan bayi baru lahir agar tumbuh kembang optimal, serta aktivitas fisik ibu hamil (Saidah, 2016). Berdasarkan uraian di atas pelaksanaan kelas ibu hamil dengan Prenatal Yoga dapat mengurangi kecemasan ibu hamil sehingga ibu siap dalam menghadapi persalinan dengan aman dan nyaman. (Kemenkes, Pedoman Kelas Ibu Hamil, 2014).

\section{Simpulan}

Pada penelitian ini diketahui bahwa sebelum dilaksanakan kegiatan kelas ibu hamil sebagian besar ibu memiliki kecemasan sedang, namun setelah mengikuti kelas ibu hamil dengan Prenatal Yoga di Puskesmas Ciruas Kabupaten Serang sebagian besar ibu memiliki kecemasa ringan, sehingga dapat disimpulkan yaitu intervensi kelas ibu hamil dengan prenatal yoga dapat mengurangi tingkat kecemasan pada ibu hamil trimester III. Hal ini terbukti dengan tingkat kecemasan ringan mencapai $90 \%$ sesudah diberikan kelas ibu hamil dengan prenatal yoga.

\section{Referensi}

Aeni, N. (2013). Faktor Resiko Kematian Ibu. Jurnal Kesehatan Masyarakat Vol 7 no 10, 453-459.

Fajrin, F. I. (2017). Hubungan Paritas dengan Tingkat Kecemasan Ibu Hamil Trimester III dalam Menghadapi Persalinan. Lamongan: Universitas Islam Lamongan.

Kemenkes. (2014). Pedoman Kelas Ibu Hamil. Jakarta: Dirjen Gizi dan KIA.
Kemenkes. (2017). Lakip Kesga. Jakarta: Direktorat Kesehatan Keluarga.

Lowdermilk, B. I., \& Jensen. (2004). Buku Ajar Keperawatan Maternitas . Jakarta: EGC.

Qurniasih, N. (2014). Hubungan Aktivitas Kelas Ibu Hamil Terhadap Kesiapan Ibu Hamil dalam Menghadapi Persalinan. Yogyakarta: Sekolah Tinggi Ilmu Kesehatan Aisyiah.

Saidah, H. (2016). Pengaruh Kelas Ibu Hamil Terhadap Kesiapan Persalinan Pada Ibu Hamil Trimester III di Puskesmas Sukorame. Kediri: Fakultas Ilmu Kesehatan Universitas Kediri.

Sari, A. A., \& Puspitasari, D. (2016). Hubungan Senam Yoga dengan Kesiapan Fisik dan Psikologi Ibu Hamik dalam Menghadapi Persalinan di Kelas Antepartum. Jurnal Terpadu Ilmu Kesehatan Volume 5 No.2, 110237.

Setyaningsih, P., Fitriyani, \& Ersila, W. (2016). Pendampingan Kelas Ibu Hamil dalam Upaya Meningkatkan Kesehatan Ibu dan Janin. Rakernas AIPKEMA, 294-296. 